\title{
A construção da identidade docente na educação superior tecnológica: um estudo de caso
}

\author{
Paulo Fossatti \\ Centro Universitário La Salle de Canoas \\ Suzana Trevisan \\ Instituto Federal Sul-rio-grandense
}

\section{Resumo}

Trata-se de pesquisa qualitativa, estudo de caso. Objetiva compreender o processo de construção da identidade docente dos professores do ensino superior tecnológico. 0 referencial teórico baseia-se, prioritariamente, em Tardif, Freire, Cunha, Pimenta e Frankl. Os sujeitos são professores dos cursos superiores tecnológicos. Os instrumentos utilizados para a coleta de dados são: observação, questionário e entrevista semiestruturada. A técnica de análise de conteúdo de Bardin resultou em seis categorias: saber científico; saber-fazer profissional; saber empírico-pedagógico; saber da humanização; ganhos existenciais e a administração do tempo cronológico. Apresenta-se uma proposta de demandas formativas.

Palavras-chave: Identidade docente. Ensino superior tecnológico. Saberes docentes. 


\section{The construction of teacher identity in technological higher education: a case study}

This qualitative case study aims at understanding the process of constructing a teacher's identity by professors in higher education in technology. The theoretical framework is based primarily on Tardif, Freire, Cunha, Pimenta and Frankl. The objects are professors in higher technological education courses. The instruments used for data collection are: observation, questionnaires and semi-structured interviews. Bardin's technique of content analysis resulted in six categories: scientific knowledge; professional know-how; empirical-pedagogical knowledge; knowledge of humanization; existential gains and the administration of chronological time. A proposal of training demands is presented.

Keywords: Teacher identity. Higher education in technology. Teachers' knowledge.

\section{La construcción de la identidad docente en la educación superior tecnológica: un estudio de caso}

Se trata de una investigación cualitativa: un estudio de caso. Tiene como objetivo el proceso de construcción de la identidad docente de los profesores de educación superior tecnológica. El marco teórico se basa principalmente en Tardif Freire, Cunha, Pimenta y Frankl. Los sujetos son profesores de cursos superiores tecnológicos. Los instrumentos utilizados para la recopilación de datos son: observación, cuestionario y entrevistas semiestructuradas. La técnica de análisis de contenido de Bardin resultó en seis categorías: conocimiento científico; conocimiento profesional; conocimiento empírico-pedagógico; conocimiento de humanización; ganancias existenciales y la administración del tiempo cronológico. Se presenta una propuesta de demandas de formación.

Palabras-clave: Identidad docente. Educación superior tecnológica. Conocimiento de docentes. 


\section{Introdução}

Este artigo é resultado da pesquisa desenvolvida no programa de mestrado em educação do Centro Universitário La Salle - Unilasalle, na linha de formação de professores, teorias e práticas educativas. A questão que nos ocupa neste artigo é: como se dá o processo de construção da identidade docente dos professores do ensino superior tecnológico, profissionais sem formação inicial voltada para a docência? Temos como objetivo geral compreender o processo de construção da identidade docente dos professores do ensino superior tecnológico, sem formação voltada para a docência, em uma instituição do Sul do Brasil.

Trata-se de um estudo de caso, numa abordagem qualitativa, por privilegiar a análise de microprocessos e por permitir a flexibilidade quanto às técnicas de coleta de dados: observação simples, questionário e entrevista semiestruturada.

0 referencial teórico baseia-se nos estudos de Maurice Tardif, que denomina como heterogêneo e plural o saber profissional docente, já que envolve diferentes conhecimentos e um saber-fazer bastante diverso. Por fim, temos presentes os ideais propostos por Paulo Freire que, na verdade, vêm ao encontro dos ideários citados anteriormente: a pluralidade dos saberes docentes, a necessidade de reflexão crítica sobre a prática e o compromisso de criarmos possibilidades para que os alunos construam seu conhecimento.

Os sujeitos dessa pesquisa são professores que estavam lotados em cursos superiores tecnológicos, no primeiro semestre de 2012, de uma instituição de ensino superior do Sul do Brasil. A coleta de dados contou com três instrumentos: a observação simples, o questionário e a entrevista semiestruturada. Depois de o projeto ter sido aprovado pela banca de qualificação, receber as autorizações do comitê de ética e da pró-reitora acadêmica da instituição de educação superior (IES) em foco, iniciamos a coleta de dados mediante dois outros recursos.

Para realizar o processo de interpretação dos dados, utilizamos a técnica de análise de conteúdo proposta por Bardin (1988). Os dados resultaram em seis categorias que ilustram elementos constituintes da identidade docente: 1) o saber científico; 2) o saber-fazer profissional; 3) o saber empírico-pedagógico; 4) o saber da humanização; 5) os ganhos existenciais; e 6) a administração do tempo cronológico. Na discussão desses dados, trazemos ainda outros autores que enriquecem as reflexões, como Pimenta, Cunha, Jesus, Marchesi e Frankl.

\section{Cenário da educação superior na atualidade}

Vivemos em um tempo de tal maneira particular na história que, quando pensamos na situação da ciência, temos a impressão de que, devido ao imenso 
salto científico dado ao longo do século XX e no início deste século, aqueles anos que nos precederam parecem pré-história.

Sem dúvida, uma das iniciativas mais relevantes em relação ao nível superior foi a criação dos cursos superiores tecnológicos. Os decretos $n^{\circ} 2.208$ (de 17 de abril de 1997) e $n^{\circ} 5.154$ (de 23 de julho de 2004) definem esse nível como graduação específica, no sentido de formar profissionais para atender campos delimitados do mercado de trabalho. Entretanto, a criação desses cursos também trouxe uma mudança significativa do paradigma de formação discente: se o fator econômico (e, portanto, a preparação da mão-de-obral era o espectro mais importante no século passado, no ensino superior tecnológico o foco passa ser a possibilidade de inclusão social por meio de um ensino voltado para a formação de profissionais aptos a desenvolver atividades de uma determinada área de maneira plena e inovadora.

Nesse sentido, Libâneo (2006, p. 25) contribui com a ideia de que a educação deve "voltar-se para as novas realidades, ligar-se ao mundo econômico, político, cultural e, ao mesmo tempo, tornar-se um baluarte contra a exclusão social". Ele afirma ainda que a escola tem o papel de oferecer condições cognitivas e afetivas para que os alunos sejam capazes de avaliar e criticar as condições de produção e difundir o saber científico.

Entendemos que o exercício da profissão docente influencia diretamente na construção desse aluno crítico e conhecedor da ciência. Por isso, particularmente nesta pesquisa, nossa preocupação recai sobre a construção da identidade de professores da educação superior tecnológica.

\section{Educação profissional de nível tecnológico no Brasil}

O século XX marca a consolidação do ensino voltado para o mercado de trabalho. Em 1906, foi entregue ao Congresso Nacional um projeto de promoção do ensino prático industrial, agrícola e comercial. Essa iniciativa previa a criação de campos e oficinas escolares. Os alunos do ginásio aprenderiam, então, o manuseio de instrumentos de trabalho.

Considerando-se os limites da economia e da sociedade daquela época, “a educação profissional e tecnológica, por meio dessas escolas, desempenha papel relevante no enfrentamento dos desafios surgidos ao longo do processo de desenvolvimento econômico" (Brasil, 2010, p. 10). É somente nas décadas de 30 e 40 que o Brasil sofre uma mudança econômica que afeta diretamente o desenvolvimento desse tipo de educação: a economia desloca seu eixo de atuação para a área industrial e a existência dessas escolas profissionalizantes vai ao 
encontro dos interesses econômicos. (Brasil, 2010)

Simões e Castanho (2010, p. 5) apontam que a nova burguesia formada após o final da Primeira Grande Guerra exige acesso à educação. Os novos ricos desprezam a formação tecnicista e desejam uma educação acadêmica e elitista. Por outro lado, o mesmo autor destaca que "o operariado exige um mínimo de escolarização, e começam as pressões para a expansão da oferta de ensino".

Somente após o ano de 1942, a formação profissional passa a ser um nível equivalente ao secundário. No final da década de 50 , as escolas industriais e técnicas ganham autonomia didática e de gestão e são nomeadas escolas técnicas federais. A intensificação da formação de profissionais ocorre nesses anos, já que o processo de industrialização está "a todo vapor" no Brasil.

A década de 70 foi um período de fortes mudanças nas políticas da educação profissional. Simões e Castanho (2010, p. 8) ressaltam que o grande objetivo do governo, naquela época, era "colocar o Brasil no sistema do capitalismo internacional, tratando a educação como capital humano". Dessa forma, a educação atenderia às exigências sociais de economia, de tempo, de esforços e de custos.

Sofremos, entretanto, uma retração do desenvolvimento, um desequilíbrio da economia nos anos 80 e no início da década de 90 . É somente na segunda metade da década de 90 que começa o processo de mudança do modelo educacional profissionalizante. 0 debate realizado em algumas escolas federais tinha por objetivo promover uma reforma não só curricular, mas também que apontasse para uma nova pedagogia institucional. " 0 principal objetivo era alinhar as políticas e ações das instituições ao cenário com destaque para aquele que demarcava as demandas sociais, locais e regionais". (Brasil, 2010, p. 12)

Por isso, mesmo que, em 1969, o Decreto-Lei n 547/69 já autorizasse a organização e funcionamento de cursos superiores profissionais de curta duração, somente em outubro de 2000 a proposta de diretrizes curriculares nacionais para a educação profissional de nível tecnológico foi encaminhada à deliberação do Conselho Nacional de Educação. Mudanças ao modelo anterior de ensino tecnológico foram propostas neste documento a fim de tornar o ensino coerente com as necessidades de nosso tempo.

O Parecer CNE/CES n 436/01, homologado pelo Ministério da Educação em abril de 2001, destaca que o curso superior de tecnologia deve formar um profissional apto a desenvolver atividades de uma determinada área profissional de maneira plena e inovadora. Além disso, afirma que a permanente ligação destes cursos com o meio produtivo faz com que eles sofram contínua atualização, renovação e autoestruturação. O Parecer CNE/CP n 29/2002 chama a atenção para a importância de delimitar e esclarecer critérios e referenciais suficientemente claros e de responsabilidade das instituições de ensino superior. 


\section{A formação e os saberes docentes}

Imbernón (2010, p. 13) pontua que a preocupação com a formação dos professores é bastante antiga. Conforme o autor, ela foi exercida "desde a Antiguidade, desde o momento em que alguém decidiu que os outros educariam os seus filhos e esses outros tiveram que se preocupar em fazê-lo".

A importância da formação inicial para o sucesso do processo de ensino e aprendizagem é consenso entre os pesquisadores. Mizukami (2002) entende que o papel desta formação é essencialmente fornecer bases que contribuam para a construção de um conhecimento pedagógico especializado. Porém, embora necessária, a formação inicial não se mostra suficiente se encararmos a formação dos professores para além da aquisição de conhecimentos técnicos.

Além disso, a profissão docente exige preparo e reflexão contínua sobre o seu fazer, sendo mais do que um fazer vocacionado. Desse modo, a formação continuada tem papel decisivo na construção de um profissional reflexivo. Imbernón 12010 , p. 13) diz que essa formação é um processo mais recente historicamente, que contempla:

[...] a inquietação de saber como [...], de que maneira, com quais conhecimentos, com quais modelos, quais modalidades de formação são mais inovadoras e, sobretudo, a inquietação de ter a consciência de que a teoria e a prática da formação devem ser revisadas e atualizadas [...].

Gauthier e Tardif, investigadores dos saberes docentes, acreditam na ideia de que os professores têm uma base de conhecimento (knowledge base). Essa concepção foi fundamental para os movimentos de reforma na formação inicial dos professores da educação básica que ocorreu nos Estados Unidos e no Canadá no final dos anos 80 . Dentre outros objetivos, essa reforma buscava a afirmação de um status profissional para os profissionais da educação, superando a ideia do fazer docente como um fazer vocacionado.

Almeida e Biajone (2007) destacam que acreditar no modelo de racionalidade prática implica, necessariamente, a valorização do conhecimento dos professores e o reconhecimento de tais como colaboradores e parceiros nas práticas formativas. Esses autores trazem algumas pesquisas acerca da formação de professores, citando as contribuições dos três autores citados anteriormente que criaram diferentes concepções e tipologias sobre os saberes docentes.

Gauthier afirma que o desafio da profissionalização docente é exercer o ofício feito de saberes. Para ele, o ensino se dá “como a mobilização de vários saberes que formam uma espécie de reservatório que é utilizado para responder às 
exigências das situações concretas de ensino" (Almeida; Biajone, 2007, p. 285). Ele vê o professor como sujeito capaz de deliberar, julgar e decidir sobre a ação a ser tomada, pois é munido de saberes e confronta-os com a situação que se coloca.

Maurice Tardif (2012) questiona quais devem ser os saberes necessários para a atuação profissional dos professores. Ele acredita que seus saberes são parte de um processo em permanente construção ao longo da carreira profissional. Como esse estudo tem como participantes profissionais provindos de formação técnica, elegemos Tardif na tentativa de enriquecer a compreensão da construção da identidade docente.

Tardif (2012) define o saber dos professores como um saber social porque é compartilhado por um grupo de agentes, porque seus objetos são objetos sociais, na medida em que ele atua com sujeitos e em função de um projeto de transformar, educar e instruir seus alunos, e, finalmente, porque "o que" e "de que maneira ensinar" mudam ao longo do tempo e conforme as mudanças sociais. Ele ainda aponta para o fato de que os saberes dos professores dependem das condições nas quais o trabalho deles se realiza, assim como dependem da personalidade e da experiência profissional de cada indivíduo.

Esse mesmo teórico denomina o saber profissional docente como heterogêneo e, na medida em que envolve conhecimentos e um saber-fazer bastante diversos: “[...] o saber profissional está, de certo modo, na confluência de vários saberes oriundos da sociedade, da instituição escolar, dos outros atores educacionais, das universidades etc." (Tardif, 2012, p. 19). Esse saber docente é composto por vários outros saberes provenientes de diferentes fontes: da formação profissional, de saberes disciplinares, curriculares e experienciais.

Nesse sentido, a formação docente ultrapassa os parâmetros mínimos da lei que prevê que o professor que atua no ensino superior tecnológico deverá ter a mesma formação exigida para a docência no ensino superior: “[...] A preparação para o exercício do magistério superior far-se-á em nível de pós-graduação, prioritariamente em programas de mestrado e doutorado" (Brasil, 2002, p. 52). Muito mais do que obter o título de mestre ou doutor, saberes diversos fazem parte da construção da sua identidade.

Os saberes da formação profissional são transmitidos pelas instituições de formação de professores. Relacionados ainda a estes saberes, há aqueles provenientes de reflexões sobre a prática educativa, apresentando-se como doutrinas. Esses são chamados saberes pedagógicos. Eles “articulam-se com as ciências da educação [...], na medida em que eles tentam [...] integrar os resultados da pesquisa às concepções que propõem a fim de legitimá-las". (Tardif, 2012, p. 37)

Os saberes disciplinares são aqueles que correspondem aos diversos 
campos do conhecimento. Eles são transmitidos nos cursos universitários independentemente se ele for relacionado à área da educação ou à área técnica. Estes saberes "emergem da tradição cultural e dos grupos sociais produtores de saberes". (Tardif, 2012, p. 38)

Já aqueles que correspondem aos objetivos, métodos, conteúdos e discursos da instituição escolar, apresentando-se concretamente sob a forma de programas escolares (objetivos, conteúdos e métodos), e que os professores devem aprender e aplicar são chamados saberes curriculares.

Mas, sem dúvida, são os saberes experienciais que surgem como "núcleo vital do saber docente, núcleo a partir do qual os professores tentam transformar suas relações de exterioridade com os saberes em relação de interioridade com a sua própria prática" (Tardif, 2012, p. 54). Bem como diz o nome, os saberes experienciais são aqueles que se originam na prática cotidiana da profissão e são validados por ela.

\section{Procedimentos metodológicos}

A pesquisa que gerou este artigo é um estudo de caso tipo qualitativo. Martins (2004) afirma que tal metodologia privilegia a análise de microprocessos, realizando estudos sobre as ações sociais, individuais e em grupo. Stake (1998) explica que tal procedimento metodológico define-se como um estudo de um caso singular, na sua complexidade e particularidade, e tem como objetivo compreender as atividades ou atitudes nessas determinadas circunstâncias. Yin (2010, p. 32), por sua vez, destaca que:

0 estudo de caso é preferido no exame dos eventos contemporâneos, mas quando os comportamentos relevantes não podem ser manipulados. 0 estudo de caso conta com muitas das mesmas técnicas que a pesquisa histórica, mas adiciona duas fontes de evidência geralmente não incluídas no repertório do historiador: observação direta dos eventos sendo estudados e entrevistas das pessoas envolvidas nos eventos.

Tal pesquisa teve como objetivo geral compreender o processo de construção da identidade docente dos professores do ensino superior tecnológico, sem formação voltada para a docência, em uma instituição do Sul do Brasil. Tratandose de um estudo de caso, desenvolvemos a pesquisa em uma instituição de ensino superior do Sul do Brasil. Esse estabelecimento iniciou suas atividades neste nível há algumas décadas e mantém sua trajetória ligada à educação até os dias de hoje. Os primeiros cursos a serem implantados tinham ênfase na preparação de 
professores. Tal iniciativa demonstra a preocupação com o cenário educacional desde o início de sua trajetória. Outro fato relevante que ilustra sua preocupação com a formação docente foi a prioridade na implantação do stricto senso voltado para a área da educação.

Portanto, por tratar-se de uma IES que acredita e se preocupa com a educação e com a formação dos professores, e crê que a formação dos alunos não se dá exclusivamente preparando-os com conhecimento científico, afirmando uma visão educacional humanística, justificamos a escolha de tal instituição como cenário da pesquisa.

Os sujeitos protagonistas foram os 14 professores que, voluntariamente, concordaram em participar do estudo e que estavam lotados, no primeiro semestre de 2012, em cursos superiores tecnológicos da instituição acima referida. Cabe salientar que alguns dos cursos oferecidos em tal estabelecimento estão em fase de implantação. A escolha dos sujeitos centra-se no fato de que são professores que possuem uma formação inicial não docente, ou seja, são profissionais formados em cursos de bacharelado - em sua grande maioria são pós-graduados em áreas técnicas -, e que atuam na área da educação sem terem tido a oportunidade de frequentar um curso específico de formação pedagógica.

Conforme levantamento prévio, no segundo semestre de 2011, cerca de 40 profissionais atuaram nos cursos, mas a maioria estava lotada em outros cursos superiores. Somente 14 professores participaram por cumprirem as delimitações propostas por esse estudo: a) aceitaram, voluntariamente, participar; b) são profissionais de formação acadêmica técnica (não licenciados); c) estavam lotados, no primeiro semestre de 2012, em um dos cursos superiores tecnológicos que participam da pesquisa.

A coleta de dados deu-se por meio de observações simples, questionário e entrevista com questões semiestruturadas, com foco nos saberes docentes. Para a escolha dos entrevistados, a fim de aprofundar as informações obtidas nos diversos instrumentos da pesquisa, realizamos um sorteio aleatório com os nomes dos professores lotados no mesmo curso, que aceitaram participar, a fim de ter um representante de cada curso, totalizando cinco professores entrevistados.

\section{Achados da pesquisa}

\section{0 saber científico}

Por muito tempo, os conhecimentos e habilidades relacionados à rigidez científica foram muito valorizados no cenário educacional. Ainda hoje esse 
paradigma é comumente valorizado na produção e no estudo da ciência no ensino superior. Os professores participantes reafirmam a importância do saber científico para o exercício da profissão docente. Cunha (2004, p. 527), por sua vez, dialoga com as ideias apresentadas quando afirma que “[...] dos docentes universitários costuma-se esperar um conhecimento do campo científico de sua área, alicerçado nos rigores da ciência [...]".

Pertencentes a uma sociedade marcada pela fluidez das informações, os professores encontram o desafio de estarem sempre reconstruindo seus conhecimentos científicos. A narrativa do professor um (P1) ilustra a opinião do grupo em foco: "O desafio constante na minha área é manter-se atualizado. [...] A gente precisa estar sempre se atualizando".

Nesse sentido, Freire (1996, p. 28) nota a necessidade de reconhecermo-nos como eternos aprendizes, porque os saberes científicos são dinâmicos e sofrem transformações na razão proporcional em que o tempo passa:

[...] histórico como nós, o nosso conhecimento do mundo tem historicidade. Ao ser produzido, o conhecimento novo supera outro que antes foi novo e se fez velho e se "dispõe" a ser ultrapassado por outro amanhã. Daí que seja tão fundamental conhecer o conhecimento existente quanto saber que estamos abertos e aptos à produção do conhecimento ainda não existente.

\section{0 saber-fazer profissional}

O conhecimento da dinâmica do mercado de trabalho e a capacidade de trazêla e ilustrá-la em sala de aula são apontados pelos professores em foco como saberes fundamentais para a atuação no ensino superior tecnológico.

0 professor um (P1) justifica sua crença dizendo que o conhecimento de mercado é importante "porque o aluno vai perguntar sobre situações bem práticas, e quem está no mercado vai trazer os exemplos que alunos querem ouvir".

Como, legalmente, o nível de ensino em foco é responsável pela formação de profissionais inovadores (Brasil, 2001), o grupo julga necessária a interface do conhecimento científico e do conhecimento da prática profissional extradocente para que se alcance tal objetivo, como ilustra a fala do professor cinco (P5):

[...] eu acho que esse professor tem que ter vivência de mercado de trabalho. [...] ele tem que ter uma bagagem prática. Esses cursos são rápidos, os alunos têm uma necessidade de aplicação imediata, de visualizar exemplos. São alunos, na maior parte, jovens com pouca experiência, então a gente não pode ficar só na parte teórica. [...] a contribuição de um professor que é totalmente acadêmico, no tecnólogo, não é tão grande quanto a daquele que consegue mesclar formação e experiência. 
0 professor três (P3) aponta que o link entre a academia e a vida profissional faz com que os professores consigam não só atingir o objetivo de incentivar a produção e a inovação científico-tecnológica, mas também facilitar a aprendizagem dos alunos.

Parece, portanto, que trazer experiências reais do mercado de trabalho mostra-se como um convite à aplicação imediata daquele conhecimento em um determinado contexto. Maffessoni (2010, p. 33) chama a atenção do leitor:

A educação e a formação para o trabalho, portanto, definem e estimulam as competências individuais, as habilidades das pessoas frente às situações, desafios e inovações, de forma conjugada com o conjunto de experiências, valores e habilidades sociais dos profissionais - elementos igualmente úteis aos sistemas de educação e qualificação.

A característica da atuação concomitante no mercado de trabalho e na docência faz com que os professores do ensino tecnológico sejam diferentes daqueles que atuam exclusivamente no ensino superior. Na opinião do professor oito (P8), “os cursos tecnólogos exigem uma constante atualização em relação ao que acontece no mercado de trabalho. Portanto, essa sintonia em relação às empresas é fundamental para a prática docente".

Deste modo, os professores em foco acreditam que situações reais e exemplos da futura vivência profissional acabam motivando os alunos do ensino superior tecnológico. Por isso, o saber-fazer profissional enriquece significativamente sua atuação.

Na mesma direção, Cunha observa a importância de refletirmos sobre a formação do professor universitário. A ideia de que quem fosse um bom profissional seria, consequentemente, um bom professor deu sustentação à lógica do recrutamento dos professores porque "[...] diferentemente dos outros graus de ensino, esse professor se constituiu, historicamente, tendo como base a profissão paralela que exerce ou exercia no mundo do trabalho". (Cunha, 2004, p. 526)

A fala do professor cinco (P5) elucida a opinião de que não apenas os saberes das categorias já apresentadas bastam para o exercício docente:

A vivência de mercado é essencial, mas poderia ser melhor se cada professor pudesse buscar a formação na área da educação, porque a maioria dos professores é das áreas de administração e contabilidade e nunca teve contato com a parte de educação, de aprendizagem. [...] Eu vejo que, se houvesse alguma formação nessa área, seria ainda melhor. 


\section{0 saber empírico-pedagógico}

Revelando-se como uma peça fundamental da estrutura plural e heterogênea do saber docente, os saberes didático-pedagógicos foram reconhecidos pelos professores participantes da pesquisa, como ilustra a fala do professor onze (P11): “Sinto que o meu principal desafio é ter um norte pedagógico para seguir. Sinto falta disso [...]".

Os sujeitos da pesquisa são profissionais provindos de uma formação técnica (não voltada para a docência) e, portanto, constroem seus conhecimentos didáticopedagógicos amparados: al nas experiências vivenciadas como alunos e, por isso, espelhados em professores que foram marcantes em sua vida; b) na troca de experiências com seus pares; c) mediante um método empírico de ensaio e erro.

As experiências como alunos, especialmente no nível superior, foram apontadas pelos participantes como referência tanto para a escolha, como para a aprendizagem da profissão em questão. Também reconhecem a importância de professores positivamente exemplares na construção da sua identidade docente.

As experiências vivenciadas no papel de aluno influenciam a construção dos saberes didático-pedagógicos. Os professores acessam suas lembranças (retraduzidas pelo distanciamento temporal) e crenças construídas ao longo da vida escolar. A ideia de que os saberes sobre a prática do ofício docente são intimamente relacionados com as experiências no papel de aluno é destacada por Tardif (2012, p. 20):

Antes mesmo de ensinarem, os futuros professores vivem nas salas de aula e nas escolas - e, portanto, em seu futuro local de trabalho - durante aproximadamente 16 anos (ou seja, em torno de 15.000 horas). Ora, tal imersão é necessariamente formadora, pois leva os futuros professores a adquirirem crenças, representações e certezas sobre a prática do ofício de professor, bem como sobre o que é ser aluno.

Nesse sentido, Tardif alerta que "[...] muitas pesquisas mostram que esse saber herdado da experiência escolar anterior é muito forte, que ele persiste através do tempo e que a formação universitária não consegue transformá-lo nem muito menos abalá-lo". (Tardif, 2012, p. 20)

Afirmando a diversidade da fonte que edificam seus saberes didáticopedagógicos, os participantes ressaltam também o papel da troca de experiências com os pares nesse processo. Nesse sentido, Cunha e Zanchet (2010, p. 190) acrescentam que, "em pesquisas recentes realizadas no contexto acadêmico, foi possível perceber um interesse significativo dos professores iniciantes em discutir suas práticas, repartir dificuldades e diferenças, compartilhar 
frustrações e sucessos".

Finalmente, além dos exemplos de professores e familiares resgatados na lembrança, bem como a troca com os colegas de profissão, os professores participantes dessa pesquisa reconhecem que a própria prática docente constrói seus saberes didático-pedagógicos. Por meio do método de ensaio e erro, os professores testam metodologias de aula, avaliação e outras questões didáticopedagógicas. 0 professor oito (P8), por exemplo, afirma que "muito do meu aprendizado aconteceu e continua acontecendo na prática docente".

Foi testando na prática que o professor percebeu se o método funcionaria ou não. Esses saberes da prática “formam um conjunto de representações a partir das quais os professores interpretam, compreendem e orientam sua profissão e sua prática cotidiana em todas as suas dimensões". (Tardif, 2012, p. 49)

Tardif denomina tais saberes como experienciais, porque os próprios professores os desenvolvem no exercício e prática da sua função profissional e baseiam-se no trabalho diário e no conhecimento do meio. Para tal autor, "esses saberes brotam da experiência e são por ela validados". (Tardif, 2012, p. 39)

\section{0 saber da humanização}

Uma quarta categoria surge no depoimento dos participantes. Expressões como diálogo, percepção dos alunos, conhecer, compreender e ter interesse pelos alunos contribuem para a construção da categoria relacionada ao saber da humanização.

Fossatti, Sarmento e Guths (2012, p. 79) destacam o saber da humanização como os saberes do relacionamento entre os envolvidos no processo educacional:

A educação é um processo de humanização e, desta forma, para humanizar e humanizar-se é necessário haver uma integração pessoal, pois a pessoa é um todo indissociável. A forma como o professor cuida de si é uma das bases e/ou condições para cuidar do outro que the é confiado para educar, ou seja, o aluno. Desse modo, é possível identificar o que os pesquisadores ora chamam de saberes de humanização. Estes saberes dizem respeito a todos os saberes implicados e necessários na relação entre professor-aluno. Essa atitude diante da vida diz da ordem do ser, do saber, do fazer e do conviver num todo integrado da pessoa. Os processos de humanização, que se mostram no colocar-se à disposição do outro, na postura de dar atenção, no manifestar empenho e interesse pelo bem comum, enfim, estar por inteiro diante do outro, aparecem com destaque. 
É no ensino superior que os alunos aprendem conceitos e teorias, além de desenvolverem habilidades e capacidades para que se realizem como futuros profissionais (Libâneo, 2006). Mas esse nível é também espaço de construção de relações, de constituição de valores éticos e interacionais.

Muitos dos professores em foco relatam que a aproximação dos alunos é um dos fatores que influencia na sua atuação exitosa. Eles reconhecem o saber da humanização e o interesse pelos alunos como uma característica fundamental para a atuação docente. Nesse sentido, Marchesi (2008, p. 73) ressalta que algumas habilidades do professor favorecem a participação dos alunos, tais como "[...] a sensibilidade frente aos problemas, a capacidade de promover o diálogo e de escutar e a facilidade para canalizar as inquietações e as propostas dos alunos".

0 professor que possui um saber humanizado é capaz de gerir a diversidade, valorizando as diferenças, porque entende que cada um tem a sua história e seu conhecimento. Mas, além disso, ele é capaz de auxiliar cada aluno em sua dificuldade e valorizar o que cada aluno tem de melhor.

Dessa forma, apontamos que a construção da identidade bem como a superação das dificuldades de exercício profissional passam por questões internas, como a história da vida, as crenças e angústias, bem como a interação com os pares. E é sobre este último ponto que chamamos a atenção do leitor.

\section{Os ganhos existenciais}

0 querer existencial, o gosto pela atividade docente mostraram-se muito mais relevantes na escolha da profissão. 0 professor doze (P12) ressalta o "prazer em compartilhar conhecimentos com os alunos e com os professores" como motivação da escolha pela carreira docente. 0 professor quatro (P4), por sua vez, destaca que os ganhos não materiais da profissão trazem bem-estar: "A docência me completa, alimenta minha alma, minha curiosidade e minha determinação de aprender e ensinar sempre mais".

Frankl (2003, p. 20) explica que a autotranscendência é a única maneira de realizar-se. Ela '[...] consiste no fato essencial de o homem sempre 'apontar' para além de si próprio, na direção de alguma causa a que serve ou de alguma pessoa a quem ama". Portanto, a "vontade de ajudar a mudar a realidade das pessoas para melhor", citada pelo professor seis (P6), é um exemplo de que o exercício profissional ressignifica a existência porque traz consigo a sensação de bemestar, de ter uma razão para o viver. 0 reconhecimento nutre o sentimento de bem-estar e traz subsídios para que o professor perceba sua prática como exitosa. 0 professor três (P3), por exemplo, conta um fato relevante da sua história: 
No semestre passado, eu fui o professor homenageado, sabe? É um negócio bacana porque a maioria dos alunos que me escolheram nem eram mais meus alunos. Não é porque "Ah, vamos escolher o professor porque ele vai nos passar". Isso é uma coisa que dá uma ideia de que, não só na questão do conteúdo, mas que houve uma empatia na relação professor aluno. Acho que isso é positivo e legal.

\section{A administração do tempo cronológico}

0 sentimento de bem-estar trazido pelo exercício profissional docente mostrou-se, na análise dos dados, minimizado pelo fato de que os professores acumulam diversas tarefas ou papéis sociais. Muitos dos participantes dessa pesquisa apontaram a dificuldade de conciliar o tempo para todas as atividades, seja profissional, seja de aperfeiçoamento, seja pessoal.

Como já foi dito, a maioria dos professores conjuga a atividade docente com a carreira no mercado de trabalho. Nesse sentido, Jesus (1998, p. 76) aponta que houve uma relativa diminuição da carga horária de trabalho nas últimas décadas. Em contrapartida, “o problema de 'falta de tempo' nunca se colocou com tanta pertinência na atualidade, sobretudo em atividades profissionais nas quais há flexibilidade de horário". Ele ainda afirma que, devido à diversidade e à sobrecarga de funções, muitos professores enfrentam o problema de falta de tempo. 0 hábito de trabalho durante o turno inverso, bem como aos finais de semana, mostra-se como resposta para que os professores possam dar conta de todas as exigências.

\section{Considerações finais}

Diferentes saberes foram valorizados, todos igualmente relevantes para a construção da identidade docente dos professores do ensino superior tecnológico. Os participantes apontaram seis saberes fundamentais para a sua atuação: o saber científico, o saber-fazer profissional, o saber empírico-pedagógico, o saber da humanização, os ganhos existenciais trazidos pelo exercício da profissão e a administração do tempo cronológico. Vale ressaltar que o conceito de pluralidade de saberes dialoga com os estudos de Tardif, Pimenta e Cunha, cada um com a sua contribuição.

Na discussão sobre o perfil docente requerido para o exercício profissional em cursos superiores, os dados apontam para a necessidade de um professor munido de diferentes saberes. Portanto, as seis categorias encontradas não podem ser descuidadas nos programas de formação de professores. 
Acreditamos também que os achados da pesquisa apontam para a importância de um programa de formação continuada baseado na construção do conhecimento, na interação entre o sujeito e o objeto, ou entre o professor e o exercício da sua profissão. Se pautados no paradigma bancário, de depósito de teorias educacionais e filosóficas, eles não oportunizariam a transformação e a melhoria do ensino que tanto almejamos.

Acreditamos que tais programas necessitam ser revisitados no sentido do questionamento: Será que eles atendem as demandas atuais expostas pelos professores? Os professores têm tido voz e autoria na preparação desses programas?

Precisamos continuar com o espírito investigativo no processo de formação continuada para ir esculpindo perguntas e respostas que contribuam para a formação docente e para a construção de sua identidade, especialmente nos cursos tecnológicos.

\section{Referências}

ALMEIDA, Patrícia Cristina Albieri de; BIAJONE, Jefferson. Saberes docentes e formação inicial de professores: implicações e desafios para as propostas de formação. Educação e pesquisa, São Paulo, v. 33, n. 2, p. 281-295, maio/ago. 2007. BARDIN, Laurence. Análise de conteúdo. Lisboa: Edições 70, 1988.

BRASIL. Catálogo Nacional de Cursos Superiores de Tecnologia. Secretaria da Educação Profissional e Tecnológica. Ministério da Educação, Brasília, 2010.

BRASIL. Parecer CNE/CP: 29/2002, Diretrizes Curriculares Nacionais Gerais para a Educação Profissional de Nível Tecnológico. Relator: Conselheiro Francisco Aparecido Cordão. Aprovado em 03 dez. 2002. Diário Oficial da União, DF, 13 dez. 2002. Disponível em: <http://portal.mec.gov.br/cne/arquivos/pdf/cp29.pdf>. Acesso em: 15 out. 2011.

BRASIL. Parecer CNE/CES 436/2001, aprovado em 02 abr. 2001. Relator: Carlos Alberto Serpa de Oliveira, Antonio MacDowell de Figueiredo e Vilma de Mendonça Figueiredo. Diário Oficial da União, DF, 6 abr. 2001, Seção 1E, p. 67. Disponível em: $<$ http://portal.mec.gov.br/cne/arquivos/pdf/CES0436.pdf>. Acesso em: 03 out. 2011.

CUNHA, Maria Isabel da. Diferentes olhares sobre as práticas pedagógicas no Ensino Superior: a docência e sua formação. Revista Educação, Porto Alegre, RS, v. 27, n.3 (54), p. 525 - 536, set./dez. 2004.

CUNHA, Maria Isabel da; ZANCHET, Beatriz Maria Boéssio Atrib. A problemática dos professores iniciantes: tendência e prática investigativa no espaço universitário. 
Revista Educação, Porto Alegre, RS, v. 33, n. 3, p 189 - 197, set./dez. 2010. FOSSATTI, Paulo; SARMENTO, Dirléia Fanfa; GUTHS, Henrique. Saberes docentes e a docência na Sociedade contemporânea: olhares discentes. Comunicações, Piracicaba, v. 19, n. 1, p. 71-85. jan/jun 2012.

FRANKL, Viktor Emil. Sede de sentido. 3. ed. São Paulo: Quadrante, 2003.

FREIRE, Paulo. Pedagogia da Autonomia: Saberes necessários à prática educativa. São Paulo: Paz e Terra, 1996.

IMBERNÓN, Francisco. Formação continuada de professores. Porto Alegre: Artmed, 2010.

JESUS, Saul Neves. Bem-estar dos professores: estratégias para realização e desenvolvimento profissional. Portugal: Porto, 1998.

LIBÂNEO, José Carlos. Docência no Ensino Superior: Compromissos e desafios da prática pedagógica. In: UNIVERSIDADE CATÓLICA DE SALVADOR. Docência no Ensino Superior: Compromissos e desafios da prática pedagógica; X e XI encontro de avaliação e planejamento pedagógico - EAPP. Salvador, UCSAL/ Quarteto, 2006. MAFFESSONI, Cristiane Calderari de Oliveira. Professores universitários de cursos tecnólogos: uma discussão dos saberes docentes. 2010. Dissertação (Mestrado em Educação) - Universidade Metodista de São Paulo, São Bernardo do Campo, 2010. MARCHESI, Álvaro. O bem-estar dos professores. Competências, Emoções e Valores. Porto Alegre: Artmed, 2008.

MARTINS, Heloisa Helena Teixeira de Souza. Metodologia qualitativa de pesquisa. Revista Educação e Pesquisa, USP, São Paulo, v. 30, n.2, p. 289-300, maio/ago. 2004. MIZUKAMI, Maria Graça Nicoletti, et al. Escola e aprendizagem da docência: processos de investigação e formação. São Carlos: EdUFSCar, 2002.

PIMENTA, Selma Garrido. Formação de professores: saberes da docência e identidade do professor. In: FAZENDA, Ivani Catarina Arantes (Org). Didática e interdisciplinaridade. Campinas: Papirus, 1998. p. 161-178

PIMENTA, Selma Garrido, et al. Docência no ensino superior: construindo caminhos. In: BARBOSA, Raquel Lazzari Leite (Org.). Formação de educadores: desafios e perspectivas. São Paulo: UNESP, 2003.

SIMÕES, Daniela Dantas Ribeiro; CASTANHO, Maria Eugênia. Ensino técnico: desde o período colonial à era neoliberal. São Paulo, 2010. Disponível em: <http://www.

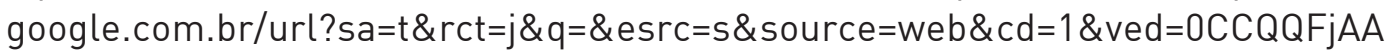
\&url=http $\% 3 \mathrm{~A} \% 2 \mathrm{~F} \% 2 \mathrm{Fwww}$.histedbr.fae.unicamp.br\%2Facer_histedbr\%2Fsemin ario\%2Fseminario8\%2F_files\%2FKrTbCuBK.doc\&ei=FJaeUPOtHoSQ9gT2yYCgBg \&usg=AFQjCNGgKT66Y_PYTx-WWCS30EWW74vvdw>. Acesso em: 16 out. 2012. STAKE, Robert. Investigación con estúdio de casos. Madrid: Morata, 1998.

TARDIF, Maurice. Saberes docentes e formação profissional. Petrópolis: Vozes, 2012. YIN, Robert. Estudo de Caso: planejamento e métodos. 4. ed. Porto Alegre: Bookman, 2010. 
Recebido em março de 2014

Aprovado em maio de 2014

Paulo Fossatti é doutor em Educação pela Pontifícia Universidade Católica do Rio Grande do Sul com Pós-Doutorado em Ciências da Educação pela Universidade do Algarve, Portugal e professor do Curso Mestrado em Educação do Centro Universitário La Salle de Canoas, Rio Grande do Sul. E-mail: irpaulodunilasalle. edu.br

Suzana Trevisan é mestre em Educação pelo Centro Universitário UNILASALLE e professora do Instituto Federal Sul-rio-grandense, Campus Sapucaia do Sul. E-mail: suzana.trevisandgmail.com 